\title{
ANÁLISE LINGUÍSTICA DE “A ROSA DE HIROXIMA”, DE VINÍCIUS DE MORAES: UMA POESIA DE CONSTRUÇÃO
}

Davidson Martins Viana Alves Mestre em Estudos de Linguagem pela Universidade Federal Fluminense (UFF) alves.dmv@gmail.com

\section{RESUMO}

Baseando-se no pressuposto de Pignatari, Campos e Campos (1975), que estabelecem que o poema construtivista é uma tensão de palavra-coisas no espaçotempo, objetiva-se analisar o poema "A rosa de Hiroxima", de Vinicius de Moraes. Esta análise se dará a partir do ponto de vista da poesia de construção, bem como os diversos níveis de análise linguísticoliterária, fônico, sintático e morfossemântico. Estes níveis mostram como o poema está associado com o seu exterior, com o ambiente; além, é claro, de reforçar a intencionalidade do autor. Haja vista que a arte só existe se houver uma intencionalidade estética para atingir a poética. Nessa perspectiva, cabe citar Silva (1968), "A literatura não fala da coisa, pois ela é a própria coisa".

Palavras-chave: linguística, literatura, poesia modernista brasileira.

\section{RESUMEN}

Basándose en el presupuesto de Pignatari, Campos y Campos (1975), que establecen que el poema constructivista es una tensión de la palabra-cosas en el espaciotiempo, se objetiva analizar el poema "La rosa de Hiroxima", Vinicius de Moraes. Este análisis se dará desde el punto de vista de la poesía de la construcción, así como los diversos niveles de análisis lingüístico-literario, fónico, sintáctico y morfosemántico. Estos niveles muestran cómo el poema está asociado con su exterior, con el ambiente; además, por supuesto, reforzar la intencionalidad del autor. Considerando que el arte sólo existe si hay una intencionalidad estética para lograr la poética. En esta perspectiva, vale citar Silva (1968): "La literatura no habla de la cosa, pues ella es la própia cosa".

Palabras-clave: linguística, literature, poesía modernista brasileña. 


\section{Introdução}

O presente trabalho propõe uma análise de um poema de Vinicius de Moraes, o grande "Poetinha", a partir do ponto de vista da poesia de construção e dos diversos níveis de análise linguístico-literária. Estes níveis mostram como o poema está associado com o seu exterior, com o ambiente; além, é claro, de reforçar a intencionalidade do autor.

Um poema de Moraes (1998) foi escolhido, estrategicamente, por este autor ser classificado sempre como um poeta romântico, que só fala do amor entre casais, da amizade e dos belos sentimentos. Busca-se evidenciar a outra faceta deste grande "Poetinha", desmistificando a noção de que ele somente escreveu com base na poesia de expressão. Aqui, neste trabalho, mostrar-se-á um Vinicius intimamente relacionado aos elementos da poesia de construção.

Os supracitados níveis linguístico-literários que serão analisados com base na construção poética vista em "A rosa de Hiroxima", de Vinicius de Moraes, são três: "nível fônico", "nível sintático" e "nível morfossemântico". A partir da noção de estratos ou níveis da linguagem poética, pretende-se explicar os mecanismos poéticos do poema, bem como o uso de suas imagens. Portanto, busca-se não definir nada. Somente tenta-se analisar e expor os elementos composicionais da escrita de um poeta que se preocupa em informar a realidade situacional de uma época sem deixar de lado as principais características da poesia de construção.

\section{Construções poéticas}




\subsection{Poesia de imitação}

A poesia de imitação é aquela que se realiza como representação da realidade, a qual se concebe como algo dado, ordenado, estável e acabado. Deste modo, cita-se Platão, com sua separação do sensível e do inteligível que leva a uma degradação da arte. Para ele, Imitação é mímesis, que, por sua vez, é mimesthai. A imitação é a capacidade de sair de si e de apresentar vários pontos de vida (mimesthai), assim confundindo o leitor, motivo pelo qual o poeta é expulso.

Para Aristóteles, a poesia não é mais a imitação das coisas, e sim das ações humanas, contudo a noção de imitação permanece na produção poética. Para a poesia de imitação, em sua primeira fase, o verdadeiro é o natural - que vem da natureza -, e o natural é o racional. A natureza é a expressão da verdade. A razão é análoga à natureza, portanto apenas a ordem racional pode traduzir a ordem natural. Logo, conclui-se que não há beleza sem razão.

Algumas composições da imitação se constituem com uma norma na qual a forma vira fôrma, com a prevalência do intelectual sobre o emocional, com certa superficialidade e convencionalismo. Além de uma busca de formas naturais, como por exemplo, nos gêneros pastorais, em que se constitui a expressão mais adequada da naturalidade pelo encontro da simplicidade com a tradição clássica, corroborando todo o dito no parágrafo anterior.

Ainda analisando a concepção de poesia de imitação, é importante comentar sobre as principais características parnasianas. A principal delas é a busca pela palavra exata (do francês - le mot juste) e logo, em seguida, as outras são: o elogio da razão e da ordem; sintonia com o mundo, sentimento de adequação e propriedade; senso do real em sua 
materialidade/plasticidade; a palavra é igual a coisa; a poesia é igual a espelho, assim, tão logo, evidencia-se a noção da arte como representação e não como criação, pois a poesia também é igual à imitação, a verdade está relacionada com algo puramente objetivo, formal e lógico, compondo um caráter universalista da arte e retornando ao padrão clássico.

Isso tudo se comprova com a celebração do equilíbrio e da proporção, com a correção gramatical e métrica - medida perfeita, alexandrino clássico, rimas ricas e formas fixas - em que a realidade se concebe como estática e ordenada. Por fim, a composição de um soneto é a consumação total do espírito parnasiano.

\subsection{Poesia de expressão}

"A poesia é o transbordamento espontâneo de sentimentos intensos." (WORDSWORTH; COLERIDGE, 2005 [1798], tradução nossa)

A supracitada definição do poeta Wordsworth promove a ruptura com vinte e cinco séculos de tradição mimético-pragmática. Nesta nova orientação poética, a emoção e a expressão compõem os principais pilares. Nela, a poesia é o extravasamento, a expressão do que vai dentro do poeta, o interno tornado externo. Ela procede da alma, que comunica sua energia criativa ao mundo.

Imitação não é poesia! Entre o poeta e a natureza, deve ser criada uma reciprocidade, em que aquele não imita esta, mas cria um cenário compatível com sua alma de modo que um exprime o outro. Deste modo, compreende-se que o avanço radical se dá no modo de entender a literatura, pois ela já não é representação da 
realidade, mas sim criação de realidades. O mundo não está pronto. $O$ ato poético é invenção de mundos. A imaginação assume o centro do processo criador, que possui imagens mais decorativas e convencionais.

A partir dessa composição imagética, constata-se que a passividade chega ao fim e que perceber já é intervir no real. A realidade imagética não é "pintada" ou "descrita", mas interpretada e transcriada. Logo, assume-se o significado do nome poeta em sua plenitude. Ele é aquele que faz, plasma, modela, como um "projetor irradiante" (metáfora que substitui a do espelho). O poeta se imprime na face do universo.

Como exemplificação deste tipo de poesia, na perspectiva deste trabalho, pode-se dizer que Tomás Antônio Gonzaga é considerado um dos primeiros poetas a escrever uma "poesia de expressão". Em sua escrita, já se notam elementos pré-românticos, pois ele traz para a poesia arcádica um traço mais moderno, menos literário; a pesquisa da natureza se humaniza; a simplicidade de sua poesia parece dissolver-se numa prosa coloquial; a delegação poética não aborta o lirismo pessoal e tudo isto é corroborado quando o escritor surge por trás do pastor Dirceu, cuja personalidade se constrói no plano poético, tomando a si mesma como objeto de arte, tanto que em muitas odes maduras o eu é o centro.

Sabe-se que o instinto de nacionalidade atrelado ao indianismo da poesia romântica significa um rompimento com Portugal. Efetuou-se um casamento estético-ideológico, uma nova literatura atrelada a uma pátria nova. Este enlace diminuiu a força crítica e filosófica do movimento romântico, que crescia na Alemanha.

Uma tríplice aliança se impôs, associando Pátria, Língua e Literatura. A soberania política exige uma emancipação linguística que se consolidaria por uma revolução estética. O Romantismo foi um acontecimento de linguagem porque considerou como 
valor nacional a língua brasileira cada vez mais distante da portuguesa, dando forma à relação entre Língua e Ideologia.

Por outro lado, o Romantismo ainda se opõe semioticamente a si mesmo, pois sua outra face é o inverso do nacionalismo - é o egotismo total - em que as composições poéticas estão mais preocupadas com seus dramas íntimos do que com arroubos patrióticos. Os poetas dão vazão à necessidade de sonho e fuga através de imagens extravagantes aprendidas nos pioneiros Byron e Musset.

A natureza se transfigura em cenário interior e a noite acolhe os movimentos turvos do eu profundo. O poeta se afoga periodicamente num individualismo exacerbado, pois a solidão é sua grandeza. $\mathrm{O}$ autoinsulamento garante a singularidade da emoção. O poeta é um missionário, pois sua obra é missão, seja espiritual ou social.

A racionalidade e a impassibilidade saem de cena. No fim de tudo, o que move o poeta é a solidão, o silêncio, as sombras, o entardecer, o chorar, o profundo sentir, o cismar e o pensar expressão. Poesia é o extravasamento, a expressão do que vai dentro do poeta, o interno tornado externo. Ela procede da alma, que comunica sua energia criativa ao mundo.

\subsection{Poesia de construção}

"O poema construtivista é uma tensão de palavra-coisas no espaço-tempo". (PIGNATARI; CAMPOS; CAMPOS, 1975)

A poesia de construção é aquela que se realiza como coisa de palavras, edificando mediante recursos puramente formais - trama imagética, rede sonora, articulação 
fonossemântica, elementos gráficos - um mundo autônomo, que significa por si mesmo, não por uma explicitação lógico-discursiva.

Sabe-se que a composição prévia determina não apenas a estrutura do poema, mas também a sua expressão e cada elemento constitutivo. O texto pré-existe às partes como um princípio genético e o todo não é aonde se chega ou aonde se quer chegar, mas de onde se parte. A poesia deixa de ser um desenvolvimento linear no tempo e se torna uma construção arquitetônica no espaço.

O lugar de cada elemento na composição do poema, o modo pelo qual todos os elementos trabalham dentro do conjunto - produzindo efeitos de harmonia (consonâncias) ou de contraste (dissonâncias) - e a submissão de tudo à ideia-geratriz e à grande lei do equilíbrio geral são os elementos que conferem ao poema a sua unidade, é de importância capital para a criação de um mundo novo, um cosmos poético. Cita-se Poe (2011), “em toda a composição não deve escapar uma única palavra que não seja uma intenção, que não tenda direta ou indiretamente a perfazer o desígnio premeditado".

Segundo esta concepção de poesia, o movimento de cada frase deve suscitar no leitor uma disposição análoga a que engendrou o poema. Do trabalho conjunto de todos os elementos envolvidos agindo uns sobre os outros, nascem a magia e a beleza. Elas são fruto da unidade de impressão, cujas qualidades fazem da linguagem um sortilégio encantatório.

O verso não tem que reproduzir ou descrever a realidade. Ele não é o molde de nenhum objeto que existe. O verso institui um jogo sutil de relações, de reflexos, de cintilações virtuais, das quais se depreende uma realidade nova e essencial. A transposição poética permite ir além do que se é, liberando-nos do tédio em face das 
coisas - já que estas se estabelecem sólidas e preponderantes -, e oferecendo-nos a ideia dos objetos em lugar de sua realidade tirânica.

Mais uma vez, confirma-se a característica principal desse tipo de poesia aqui evidenciado, o poeta não imita nem exprime as coisas. Ao contrário, por uma espécie de criação negativa, ele anula as coisas em sua realidade tangível para não as conservar senão a essência. Assim a literatura se concebe como que uma projeção do mundo no absoluto, para além da existência "impura" das coisas e descobrindo o sistema de suas relações.

A partir de algumas reflexões, percebe-se que a estética da sugestão leva à doutrina da transposição, negando o objeto em sua existência material pelo jogo da linguagem, recriando-o como noção pura. Logo, cita-se Mallarmé (1945), "as coisas existem, nós não temos que criá-las; o que nos compete é apreender-lhes as relações; e são os fios destas relações que formam os versos e as orquestras".

Entende-se que o poeta não tem senão um meio de se tornar "reconstrutor do universo": agir sobre a linguagem. Já que em estudos poéticos a palavra não existe sozinha, por si mesma, ela se engasta no bloco da frase, colorindo-se das sugestões das palavras vizinhas. Os referidos vocábulos são empregados como valores em um quadro, de modo que criam um sistema de relações e um campo gravitacional de influências recíprocas. Escolhem-se as palavras menos por seu significado do que por sua sonoridade e, logo, criam-se sentidos com sons através de uma pesquisa de aliterações, assonâncias e paronomásias (palavras de som parecidos/aproximados).

Além disso, empreende-se um extraordinário esforço de orquestração que atende a uma exigência de síntese e se aplica não apenas aos valores sonoros, mas também aos temas. Cada tema - segundo um método de composição que se poderia chamar musical - 
aparece, desenvolve-se, enriquece-se de motivos secundários, se oculta e volta ao fim, para compor com os outros temas um verdadeiro mosaico, que procura traduzir, por exemplo, os movimentos profundos que se atam e desatam a alma humana.

Nessa perspectiva, considera-se que uma linguagem tão densa, tão concertada, em que as palavras parecem costurar-se umas às outras, é bem a imagem de um universo construído rigoroso, sem fissuras. E essa é a verdadeira e mais genuína forma de composição e "construção" poética: a poesia de construção!

\section{Análise da poesia de construção "Rosa de Hiroxima", de Vinicius de Moraes}

\subsection{No nível fônico}

Entende-se por estilo fônico o conjunto de processos sonoros que fazem da língua representativa um meio de exteriorização da linguagem afetiva. Procura-se indagar o emprego do valor expressivo dos sons: a harmonia imitativa, no amplo sentido do termo. É a fonoestilística ou como comumente chamam: fonética expressiva (CRISTÓFARO-SILVA, 2009).

Intercalando-se na estrutura do poema, disposição alternada das rimas, os versos 1ำ, 3ำ, 5ำ e 7ำ têm como primeiro elemento fônico dos vocábulos que Ihes dão início o fonema plosivo bilabial desvozeado, este, por sua vez, conota auditivamente certa repreensão e ordem, além de morfologicamente ser um verbo que está no tempo Presente Afirmativo do modo Imperativo. Para este recurso, dá-se o nome de aliteração, que é a repetição de fonema consonantal, igual ou parecido, para descrever ou sugerir 
acusticamente o que temos em mente, quer por meio de uma só palavra ou por unidades mais extensas.

Além dessa aliteração, é perceptível uma mais marcante e profunda, na qual a maior importância está em acentuar que a mesma ocorre mais na exteriorização psíquica e no apelo que na comunicação intelectiva. O repetitivo uso dos fonemas plosivos: bilabiais (/p/- desvozeado e /b/- vozeado), alveolares (/t/- desvozeado e /d/- vozeado) e velares (/k/- desvozeado e /g/- vozeado) nos vocábulos - crianças, telepáticas, cegas, inexatas, rotas, alteradas, feridas, cálidas, esqueçam, da, hereditária, radioativa, estúpida, inválida, atômico, cor e perfume - conotam incômodo e intranquilidade pelo fato de se estar pronunciando fonemas plosivos, modo de articulação que denota explosão. Os referidos vocábulos transpassam um extremo desassossego.

Outro recurso estilístico fônico é o da rima em eco, este é a repetição, com pequeno intervalo, de palavras que terminam de modo idêntico. Fato observado nos

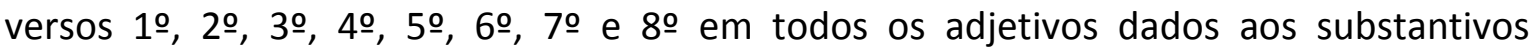
crianças, meninas, mulheres, feridas e rosas, que são: mudas, telepáticas, cegas, inexatas, rotas, alteradas, cálidas. Por conseguinte, ao desenrolar do poema, nota-se que os adjetivos supracitados são os resultados do efeito explosivo e devastador da bomba, que, por sua vez, assume o seu alter ego, a Rosa de Hiroxima.

Denota-se uma estabilidade métrica que traduz uma estabilidade emocional. Tudo gira em torno da rosa. Ela é o centro do poema. A estrofação, que admite versos livres, não é exata visualmente, no campo dos grafemas. Entretanto, no campo dos fonemas - a partir da ativação do sistema sonoro - é nitidamente visível. Está implícito, contudo é notável perceber, também, que o poema está dividido em nove dísticos/parelhas. 


\title{
2.2. No nível sintático
}

"Eu sou", diz o poeta, "profunda e escrupulosamente um sintaxista. Minha frase é o que ela deve ser e ser para sempre" (MALLARMÉ, 1945).

A estilística sintática procura explicar o valor expressivo das construções. O traço estilístico pode ser um desvio ocasional de norma gramatical vigente, mas se impõe pela sua intenção estético-expressiva de querer dizer algo mais.

Os versos apresentam-se autônomos. Isto porque a relação coordenativa faz-se implicitamente, por adição, nos oito primeiros versos. Estes são trechos independentes que evoluem progressivamente sem uma preocupação imediata com o fim (LIMA, 2010).

Ainda coerente com a autonomia das partes, a coordenação é o processo sintático mais apropriado para reunir, concatenar os objetivos do eu lírico. Tanto que, percebe-se a

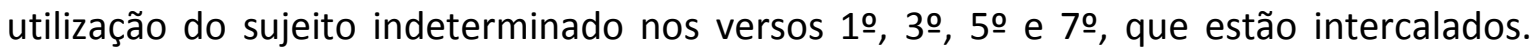
Através dessa utilização, contata-se que o eu lírico não deseja especificar seu remetente, propositalmente ele se posiciona ordenando a todos a pensarem e refletirem o fatídico dia em que a rosa foi desarmada.

Há um pleno uso de adjuntos adnominais de núcleos de objetos indiretos. Visto em:

\author{
"Pensem nas crianças / mudas telepáticas" \\ "Pensem nas meninas / cegas inexatas" \\ "Pensem nas mulheres / rotas alteradas" \\ "Pensem nas feridas / como rosas cálidas"
}


O poema é todo estruturado em orações coordenadas aditivas elípticas (construções sintáticas justapostas). Contudo, exatamente na metade do poema - no verso 9-, aparece explicitamente uma outra construção coordenada, uma adversativa.

"Mas oh não se esqueçam"

Além de ter encontrado esta informação, ao analisar minuciosamente toda a oração coordenada, vê-se um chamamento feito pelo sujeito indeterminado a todas as pessoas. Este chamamento classifica-se como vocativo e constitui, por si só, a rigor, uma frase exclamativa à parte ou um fragmento da oração, à semelhança das interjeições.

Classifica-se o referido vocativo num contexto funcionalmente apelativo, pois este se liga ao Imperativo (conteúdo volitivo da forma verbal) e em se tratando de ordem ou manifestação de desejo endereçada à pessoa com quem se fala ou a quem se dirige, não há necessidade de marcar gramaticalmente o sujeito. Veja o verso 9:

"Mas oh não se esqueçam"

Por último e não menos importante, nota-se uma abundância de objetos indiretos a partir da segunda parte do poema, do verso $10^{\circ}$ ao verso $18^{\circ}$, relacionados ao sintagma verbal “... não se esqueçam” (verso 9). Devem-se analisar, sobretudo, os adjuntos do núcleo do objeto indiretos, já que estes são os sintagmas mais significativos para a concepção do poema como um todo, pois caracterizam detalhadamente como os aspectos da "rosa". O núcleo do objeto indireto pertencente ao sintagma verbal supracitado é o seguinte: 
"Da rosa da rosa" / "Da rosa de Hiroxima"

E seus adjuntos são:

\author{
"A rosa hereditária" / "A rosa radioativa" \\ "Estúpida e inválida" / "A rosa com cirrose" \\ "A anti-rosa atômica" / "Sem cor sem perfume" \\ "Sem rosa, sem nada."
}

Através da massificada adjetivação - tanto por adjetivos quanto por locuções adjetivas -, ainda é possível destacar a tentativa do eu lírico de convencer o leitor de seu poema de que existem intensas deformidades na "rosa", esta que é pútrida e fétida, e que no fim de tudo não é nada, simplesmente "nada!".

\title{
2.3. No nível morfossemântico
}

O nível morfossemântico é aquele que busca a evidência morfológica e semântica na composição textual da obra literária. Para tanto, pode-se ater à palavra e à carga semântica que carrega e a quais implicações trazem sua existência na obra literária.

Primeiramente, "A Rosa de Hiroxima" é um poema de cunho social, como já se sabe. Nele sente-se um grito de conscientização e sensibilização, da tentativa de plasticidade tal que traduza aquela realidade catastrófica de Hiroshima. 
Nessa perspectiva, analisar-se-ão certos vocábulos, ou mesmo classes de palavras, que traduzem certa intenção poética do eu lírico para a produção de significados (ULLMAN, 1973):

(1) $O$ verbo, por exemplo, ocorre repetidas vezes no $1^{\circ}, 3^{\circ}, 5^{\circ}$ e $7^{\circ}$ versos de maneira peculiar. A forma verbal Pensem é responsável pela chamada à consciência do leitor ao que o poema quer tratar. Este verbo vem propor que se pare e se reflita direcionadamente para a profunda realidade sensível de Hiroshima. Quando se diz que o verbo Pensem propõe que se reflita direcionadamente é porque ele realmente direciona/designa a direção, instigando, inicialmente o leitor, a uma série de específicas imagens mentais, embora no terreno subjetivo da poesia. Isso acontece, por exemplo, no $1^{\circ}$ verso: "Pensem nas crianças" ou no $5^{\circ}$ verso "Pensem nas mulheres".

(2) A forma preposicional nas ocorre repetidas vezes nos $1^{\circ}, 3^{\circ}, 5^{\circ}$ e $7^{\circ}$ versos, também funcionando como parte do direcionamento que se deseja que o leitor siga. Quando no poema está "Pensem nas crianças" o eu lírico fornece, através da forma preposicional, uma indicação daquilo que será, posteriormente, o elemento central ou o objeto de destaque da atenção do leitor: o substantivo.

(3) O substantivo, por sua vez, é o elemento central que funcionará como objetodestaque. Nele, o eu lírico finalmente diz em que quer que o leitor pense. Como acontece no primeiro verso "Pensem nas crianças". 
A partir dos substantivos: crianças, meninas, mulheres, feridas; será composta uma camada poemática sensível, com a utilização de adjetivos e outros substantivos. Haja vista que a chamada camada poemática sensível é a significação causada pelo jogo morfossemântico realizado pelo artista poeta. A referida camada permite um entendimento sobre o processo ocorrido em Hiroshima: a queda da bomba no Japão, exatamente em Hiroshima e Nagasaki, e os impactos disso na humanidade.

Ao retratar as mulheres como rotas alteradas, o eu lírico chama a atenção para o que ocorreu no âmago da mulher, a sua alteração hormonal diante daquele momento de tensão inimaginável. Ainda, ao retratar as crianças como mudas telepáticas, ele diz sobre a má formação congênita dos fetos. Ou seja, se leva em conta os transtornos e as consequências que a bomba causou naquelas vidas e nas vidas que viriam.

\section{Considerações finais}

Em "Rosa de Hiroxima", recria-se a realidade da situação recriando a própria linguagem (CANDIDO, 1969). Situação esta que ocorreu na supracitada cidade japonesa que dá nome ao poema. A visão que Vinicius de Moraes possui do ocorrido é única, por esse motivo pode-se dizer que ela é singularizada. Isso acontece porque o autor não automatiza a linguagem, e sim deixa que as palavras sejam e tornem-se utensílios de comunicação, passando a compor imagens. Deste modo, definitivamente se invade o nível imagético.

As palavras são utensílios para comunicar e informar. Quando as palavras recriam e passam a produzir, e não mais possuem um valor em sua utilização, começam a ser arte. Assim, a palavra, no texto literário, transforma-se em imagem. Construções poéticas 
trabalham com a percepção, a imaginação e o imaginário. No texto literário, a ideia de signo saussuriano é subvertida, porque o significante na obra literária também possui um significado.

Tudo que está no texto é imagem da realidade!

O processo de recriação da realidade é chamado poiesis. Esta só acontece se o autor sofrer uma determinada sensação catártica. Essa é a libertação de tudo aquilo que prende a criação. No entanto, somente é possível recriar essa realidade através da linguagem.

\section{Referências}

CANDIDO, Antonio. Razão, natureza, verdade. In: . Formação da literatura brasileira (momentos decisivos). v. 1.3 ed. São Paulo: Livraria Martins, 1969. p. 43-76. CRISTÓFARO-SILVA, Thaïs. Fonética e fonologia do português: roteiro de estudos e guia de exercícios. São Paulo: Contexto, 2009.

LIMA, Carlos H. da Rocha. Gramática normativa da língua portuguesa. 48 ed. Rio de Janeiro: José Olympio, 2010.

MALLARMÉ, Stéphane. Oeuvres completes I et II. Paris: Gallimard, 1945.

MORAES, Vinicius de. A rosa de Hiroxima. In: Antologia poética. São Paulo: Companhia das Letras, 1998. p. 196-197.

PIGNATARI, Décio; CAMPOS, Augusto de; CAMPOS, Haroldo de. Teoria da poesia concreta: textos críticos e manifestos (1950-1960). São Paulo: Duas Cidades, 1975. POE, Edgar Allan. A filosofia da composição. Tradução de Léa Viveiros de Castro. São Paulo: Cia. 7 letras, 2011.

SILVA, Vitor Manuel de Aguiar. Conceito da literatura. In: . Teoria da Literatura. 2 ed. Coimbra: Almedina, 1968. 
ULLMAN, Stephen. Semântica: uma introdução à ciência do significado. Tradução de J. A. Osório Mateus. Lisboa: Fundação Calouste Gulbenkian, 1973.

WORDSWORTH, William; COLERIDGE, Samuel Taylor. Lyrical ballads, with a few other poems. 2 ed. Editado por R. L. BRETT e A. R. JONES. London/New York: Routledge Taylor \& Francis Group, 2005 [1798]. Disponível em:

<http://library.globalchalet.net/Authors/Poetry\%20Books\%20Collection/Lyrical\%20Ballad s\%20William\%20Wordsworth\%20and\%20S.\%20T.\%20Coleridge.pdf>. Acesso em: 10 mar. 2018.

Recebido em 15 de março de 2018.

Aceito em 23 de abril de 2018. 